\title{
The rainfall regime and its uncertainty in Valencia and Larnaca
}

\author{
H. Reiser and H. Kutiel \\ Laboratory of Climatology, Department of Geography and Environmental Studies, University of Haifa, Haifa 31905, Israel
}

Received: 11 April 2007 - Revised: 3 July 2007 - Accepted: 5 August 2007 - Published: 27 August 2007

\begin{abstract}
The Most Expected Rainfall Regime - MERR in a certain region is composed of various parameters regarding the annual rainfall regime in that region. The present study examines several parameters of the MERR, such as: the rainfall TOTAL, the Date of Accumulated Percentage-DAP, the Rainy Season Length-RSL, the Number of Rain-Spells-NRS, the Rain-Spell Yield-RSY, the ratio between Average and Median rainfall-AMED, the relationship between accumulated precipitation and the number of rain-spells and the DrySpell Distribution-DSD.

Two stations at the two sides of the Mediterranean basin, Valencia and Larnaca, have been used to illustrate the distribution of the above parameters across the Mediterranean.

The main conclusion of the study is that the rainfall regime at Larnaca is less uncertain as compared with the regime in Valencia. This is probably due to the fact that rainfalls are completely absent during the summer in Larnaca, which better suits the definition of a Mediterranean climate than that of Valencia.
\end{abstract}

\section{Introduction}

Many efforts have been made during recent years in studying climatic changes. The main aim of these studies was to find indications of departures from the known climatic patterns, and to understand the reasons for their occurrence. A major part of these studies dealt with rainfalls, as it has a crucial impact on the daily life in regions with water shortage, like the Mediterranean. In many studies rainfalls are usually represented by the mean annual depth, or in some cases by measures of variability (mostly the standard deviation) are added. Still, in many cases the mean annual rainfall may not be the most influential factor that determines the rainfall regime. It

Correspondence to: $\mathrm{H}$. Reiser

(hreiser@geo.haifa.ac.il) is essential to find what the "typical" rainfall regime is, or in other words, what is the Most Expected Rainfall Regime MERR, in a given region.

Rainfall Regime is a term that comprises many components, including: mean and other statistical measures of annual rainfall TOTAL, its temporal distribution, the length of the rainy season, distribution of rain-spells and their yields, distribution of dry-spells, etc. The MERR in a certain location reflects all these parameters (Paz and Kutiel, 2003).

Once the MERR is defined, it is then possible to calculate how much a season, or any other period of time, varies from the MERR and quantify extreme values of its various components, or in other words, quantify the degree of the Rainfall Regime Uncertainty-RRU. Uncertainty in climate refers to the inability to accurately determine when, where, and how intense a climatic phenomenon occurs (Paz and Kutiel, 2003).

Many studies on rainfall in the Mediterranean basin, or in parts of it, deal with the spatial and temporal rainfall distributions, mostly by characterizing the annual or seasonal rainfall (e.g., Türkeş, 1996; Steinberger and Gazit-Yaari, 1996; Esteban-Parra et al., 1998; Gonzalez-Hidalgo et al., 2001; Tomozeiu et al., 2002; Alpert et al., 2002; Maheras and Anagnostopoulou, 2003; Aviad et al., 2004; Norrant and Douguédroit, 2005; Houssos and Bartzokas, 2006). Only a few scholars analyze the dry-spells in order to understand the nature of the rainy season (Kutiel, 1985; Douguédroit, 1987; Martin-Vide and Gomez, 1999; Anagnostopoulou et al., 2003; Maheras and Anagnostopoulou, 2003; Ceballos et al., 2004).

A typical characteristic of the rainfall regime in the Mediterranean climate is a long dry period during the summer. A widely accepted definition for the Mediterranean climate states that in the winter months $(D, J, F)$ rainfall is at least three times greater than in the summer months $(\mathrm{J}, \mathrm{J}$, A) (Palutikof and Wigley, 1992; Wigley, 1992). Even in areas where there is hardly any rain in summer, either at the

Published by Copernicus Publications on behalf of the European Geosciences Union. 


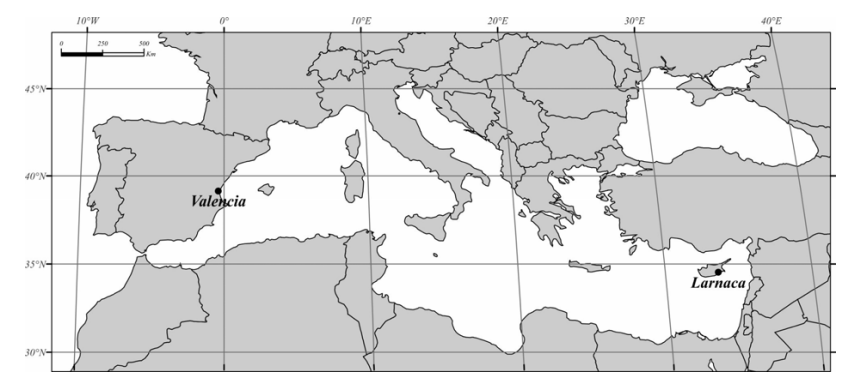

Fig. 1. Location Map.

beginning of the rainy season or at its end, we may observe some sporadic rainfall events of minute amounts, followed (at the beginning of the season) or preceded (at the end of the season) by long dry-spells. Thus, if we consider the Rainy Season Length - RSL as the period that elapses from the first rainy day until the last one, we may obtain a very long RSL, which consists mainly of long dry-spells. Most of the sporadic rainfalls at the beginning and at the end of the rainy season are of a minute value for most purposes. According to one definition, a rainy season is the time that elapses between the first and the last days with rainfall amounts that equal or exceed a specified threshold (Aviad et al., 2004).

With the objective of maintaining the continuity of the rainy period, usually the hydrological year is used rather than the calendar year. The Starting Analysis Date (SAD) is set to the 1st day of the month on which the RSL is the shortest on average. In the southern part of the Mediterranean basin the summer is dry and the SAD is set to 1 July (Reiser and Kutiel, 2007).

The present research focuses on two stations across the Mediterranean basin: Valencia in the west, and Larnaca in the east (Fig. 1). The main aims are to present the parameters of the MERR, to quantify them and to compare between the two rainfall regimes. This study practices the methodology approach, which is presented in Paz and Kutiel (2003).

\section{Data and methodology}

The rainfall data used for the analyses are daily rainfall totals from Valencia (1938-2004) and Larnaca (1947-1999) obtained from the European Climate Assessment \& DatasetECA\&D.

The data were analyzed with the aid of the Rainfall Uncertainty Evaluation Model-RUEM4 developed at the Laboratory of Climatology, Department of Geography and Environmental Studies, at the University of Haifa. RUEM4 uses daily rainfall data as input in order to calculate all the components of the MERR for any desired daily rainfall threshold (from $0.1 \mathrm{~mm}$ and above), and their time-series for the entire, or any desired period of the available dataset. Further details about RUEM4 are available at: http://geo.haifa.ac.il/ $\sim$ geoweb/RUEM\%204.pdf

In the present study, a Daily Rainfall Threshold-DRT of $1.0 \mathrm{~mm}$ was used. In addition, a rain-spell is defined as a period of consecutive days with a rainfall that is equal or above the DRT. Respectively, a dry-spell is defined as the number of days without precipitation or with less than the DRT (Kutiel, 1985). Each rain-spell is separated from the other by a dry-spell of at least one day of duration, and similarly each dry-spell is separated from the other by a rain-spell of at least one day.

The various parameters of the MERR, can be divided as follows:

Parameters related to the annual rainfall and its temporal distribution:

1. $\operatorname{TOTAL}_{(d)}$ - Average accumulated rainfall $[\mathrm{mm}]$ from all rain-spells of a given duration [days].

2. TOTAL - Mean annual rainfall

TOTAL $=\sum_{d=1}^{n}$ TOTAL $_{d}$

where, $n$ represents the longest rain-spell.

3. $\mathrm{DAP}_{(i)}-$ The temporal rainfall distribution is quantified by the median Date of an Accumulated Percentage $(i=10,20, \ldots, 90)$ of the annual rainfall (in days, since 1 July).

For example, $\operatorname{DAP}_{(10)}$ is the date when $10 \%$ of the annual rainfall was accumulated. Therefore, $\operatorname{DAP}_{(50)}$, is the mid season date, or the date in which half of the annual rainfall was accumulated.

4. RSL - Rainy Season Length [days] from the date when $10 \%$ of the annual rainfall amount until the date of $90 \%$ were accumulated.

$\mathrm{RSL}=\mathrm{DAP}_{(90)}-\mathrm{DAP}_{(10)}$

Parameters related with rain-spells:

5. $\operatorname{NRS}_{(d)}$ - The Number of Rain-Spells of a given duration [days].

6. RC - Relative Contribution [\%] of rain-spells of a given duration [days].

7. $\operatorname{RSY}_{(d)}-$ Rain-Spell Yield [mm]. The average rainfall accumulated during all rain-spells of a given duration [days]

$\operatorname{RSY}_{(d)}=\operatorname{TOTAL}_{(d)} / \operatorname{NRS}_{(d)}$ 

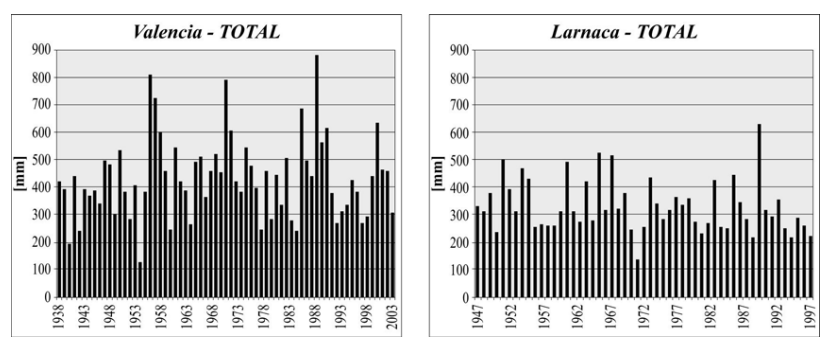

Fig. 2. Time series of TOTAL.

8. $\operatorname{RSY}_{(d)} /$ day-Rain-Spell Yield/day [mm/day]. The RSY is divided by its length to obtain the daily rainfall amount of each rain-spell.

Parameters related to extreme values of the entire data set:

9. $50 \% \mathrm{PI} / 50 \% \mathrm{PII}$ - The ratio between the accumulated percentage of rain-spells that produced the first $50 \%$ of the precipitation (PI) and the second 50\% (PII) for a given Rain-Spell Duration - RSD.

When this ratio equals 1 , it means a perfect fit, indicating that all RSYs are equal. High values of this ratio imply that a very small percentage of rain-spells contribute most of the rainfall.

10. $\operatorname{AMED}_{(d)}-\mathrm{A}$ ratio between the average rainfall of a given RSD and its median [mm].

$$
\operatorname{AMED}_{(d)}=\left(\operatorname{Average}_{(d)}-\operatorname{Median}_{(d)}\right) * 100 / \operatorname{Median}_{(d)}(4)
$$

For a symmetrical distribution this parameter equals 0 . High values of this ratio indicate a positively skewed distribution caused by few extreme cases.

A parameter that deals with dry-spells:

11. $\operatorname{DSD}_{(j, r, p)}-$ Dry-spells Distribution calculates the time [days] that elapsed from the last rainy day.

A dry-spell is calculated for each Julian day $(i)$ for a DRT $=1.0 \mathrm{~mm}(r)$ and for any desired probability $(p)$.

\section{Results and discussion}

The TOTAL in Valencia is $430.5 \mathrm{~mm}$; the maximum value recorded in the research period was $879.4 \mathrm{~mm}$, measured in $1989 / 90$ and it is nearly 7 times higher than the minimum, $126.2 \mathrm{~mm}$ in $1954 / 5$. The TOTAL in Larnaca is $328.5 \mathrm{~mm}$; the maximum rainfall amount, $629.4 \mathrm{~mm}$ in $1991 / 92$, is 4.5 times higher than the minimum amount recorded in 1972/3, $138.4 \mathrm{~mm}$ (Fig. 2).

In Valencia, $90 \%$ of the annual rainfall was accumulated as early as 26 November 1982, a month earlier than the date when only $10 \%$ of the annual rainfall was accumulated in 1981 (26 December). This reflects the inconsistency of the
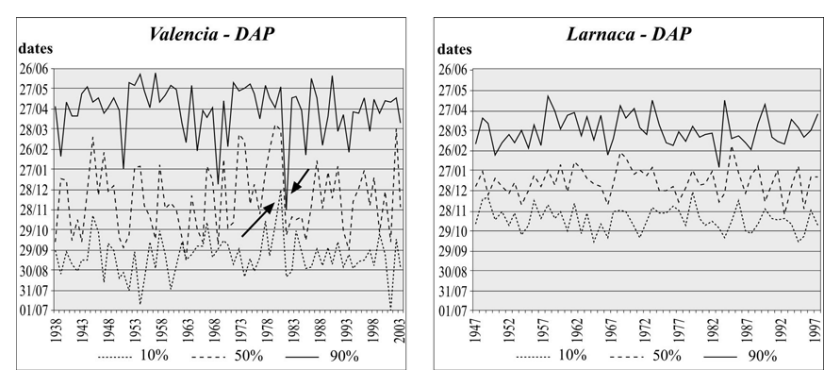

Fig. 3. Time series of $\operatorname{DAP}_{(10)}$, $\operatorname{DAP}_{(50)}$ and $\mathrm{DAP}_{(90)}$.
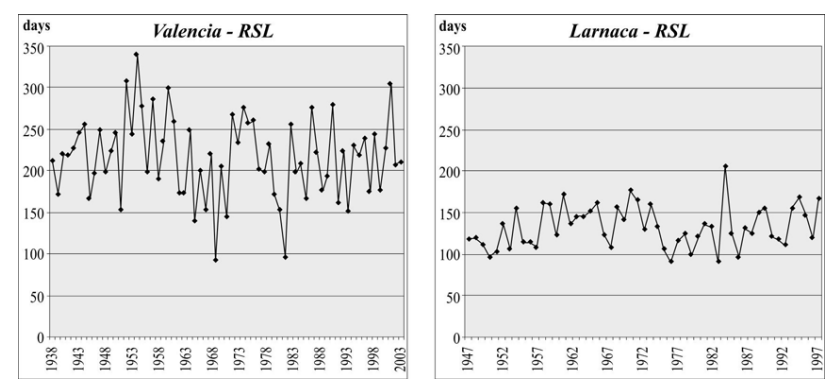

Fig. 4. Time series of RSL.

temporal distribution within the rainy season. In Larnaca, the earliest date in which $90 \%$ of the annual rainfall was accumulated was on 1 February 1985, while the latest date of accumulating $10 \%$ of the annual rainfall was 25 December 1980 (Fig. 3).

As mentioned above, the RSL is defined as the time [days] that elapsed from the accumulation of $10 \%$ of the annual rainfall until $90 \%$ were accumulated. The median RSL in Valencia consists of 221 days (7 months). The shortest season was $1969 / 70$ and it consisted of only 94 days. On the other hand, the longest rainy season (1954/55) is 1.5 times the median (344 days) and 3.7 times the shortest season. In Larnaca, the median rainy season consists of only 130 days (4.3 months). Consequently, $80 \%$ of the precipitation in Larnaca is concentrated in a very short period of time, as compared with Valencia. The difference between the shortest season (91 days in 1977/78) and the longest season (207 days in 1985/86) is smaller, as compared with Valencia (ratio of 2.3 compared with 3.7) (Fig. 4).

Another group of parameters deals with the rain-spells. As expected, the NRS decreases as the RSD increases. Figure 5 presents the NRS/yr in both stations. It can be noticed that the NRS/yr of one day, in both stations, is extremely high. In Valencia the median NRS/yr of all durations sums up to 27 rain-spells per year. The maximum value 37 (1995/96) is greater than the minimum 17 (obtained twice in 1981/82 and in $1982 / 3$ ) by a factor of 2.2. In Larnaca the median is 24 rain-spells per year, while the maximum of $29(1951 / 52)$ is larger than the minimum $15(1993 / 94)$ by a factor of 1.9 . 

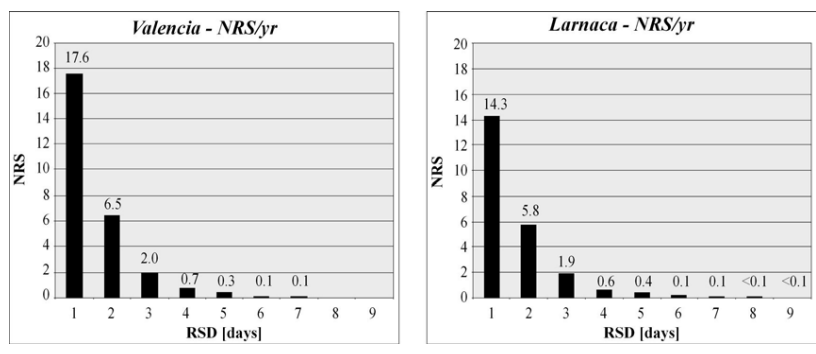

Fig. 5. Distribution of NRS/yr.
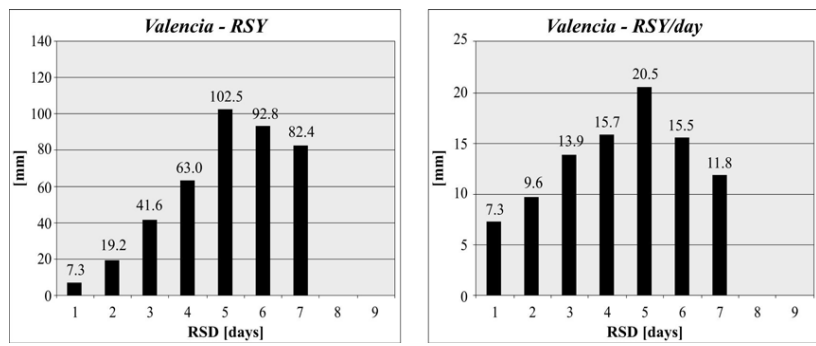

Fig. 6. Distribution of RSY and RSY/day in Valencia.

The RSY and the RSY/day are differently distributed as compared with the NRS. That is to say, the longer the rainspell, the greater its yield. This is true in Larnaca but not so much in Valencia, where rain-spells of 5 days yield the highest amount of $102.5 \mathrm{~mm}$. Rain-spells with shorter or longer duration yield less than this amount on average (Figs. 6 and 7).

The distribution of the RSY/day in Valencia is very similar to the results found in the RSY, where the rainfall amount increases up to rain-spells of 5 days and then decreases. In Larnaca this amount is more constant. The RSD of 2 days and longer yield around $12 \mathrm{~mm}$ per day (Figs. 6 and 7).

It is worth noting that the RSY in Valencia for RSDs of one to six days are higher, whereas for RSDs that are longer than 6 days they are higher in Larnaca. In Valencia no rainspells longer than 7 days have been observed at all.

The major differences between these two stations are in the distributions and extreme events of the rain-spells. In Valencia, rain-spells of two days, for example, contribute almost $29 \%$ of the total annual rainfall (Fig. 8). During the analysis period, 436 rain-spells of two days were recorded. Nine cases yielded over $100 \mathrm{~mm}$, one of them yielded the extreme amount of $285.3 \mathrm{~mm}$, whereas more than 400 two-day rainspells yielded less than $50 \mathrm{~mm}$ (Fig. 9). Similarly, in Larnaca rain-spells of two days contributed $30 \%$ of the annual rain (Fig. 8). They are more evenly distributed, i.e. 296 out of 306 two-day rain-spells recorded during the analysis period, yielded less than $50 \mathrm{~mm}$. There are two events with more than $70 \mathrm{~mm}$, and one of $100 \mathrm{~mm}$ (Fig. 9). Thus, in Valencia, the precipitation of rain-spells of two days is more diverse compared with Larnaca, where precipitation is less uncer-
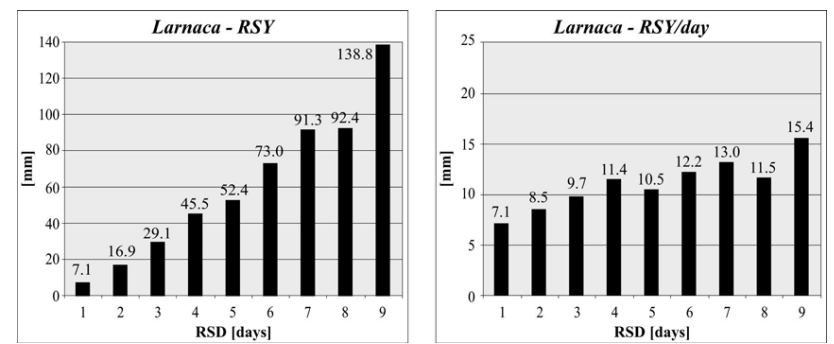

Fig. 7. Distribution of RSY and RSY/day in Larnaca.
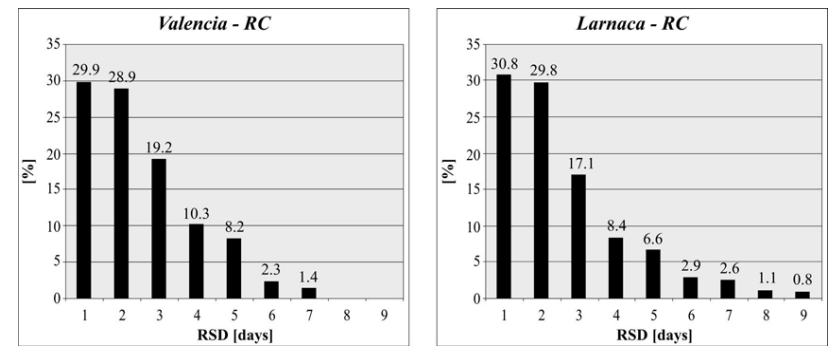

Fig. 8. The RC of various RSDs.

tain. Similar results can be observed also for other RSDs (Fig. 9).

These extreme distributions can be demonstrated also in another way. Figure 10 shows the relationship between the precipitation accumulation percentage and rain-spell accumulation percentage for $\mathrm{RSD}=1,2,3$ days. As the RSD increases, this ratio becomes less skewed. In Valencia, 50\% of the total precipitation (PI) accumulated by RSD of two days, were produced by $82.2 \%$ of the rain-spells. Whereas, the remaining $50 \%$ (PII) were produced by only $17.8 \%$ of the events, consequently, the $50 \% \mathrm{PI} / 50 \% \mathrm{PII}$ ratio is 4.5 (Table 1). In Larnaca, this ratio is smaller, only 3.6, meaning that the proportion between precipitation accumulation and rain-spell accumulation is relatively less extreme (Table 1).

Table 2 presents the AMED ratios for RSDs of 1, 2 and 3 days. Low AMED values indicate a symmetrical rainfall distribution while high AMED values indicate an asymmetric distribution (normally positively skewed) caused by several extreme events. Thus, it can be stated that Larnaca demonstrates a more symmetrical distribution as compared with Valencia and this symmetry decreases as RSD increases. Note the large asymmetry in Valencia for RSDs of 3 days, meaning several extreme events of this duration.

The last parameter of the MERR is the annual course of the median dry-spells. This parameter emphasizes the differences between these two rainfall regimes, in Valencia and in Larnaca, and their extreme values. In Valencia, the dry period is between June and September, however, there are still some sporadic rains during that period. On the other hand, Larnaca has a longer rainless dry period that lasts throughout the summer, from May until late September. In this sense, 

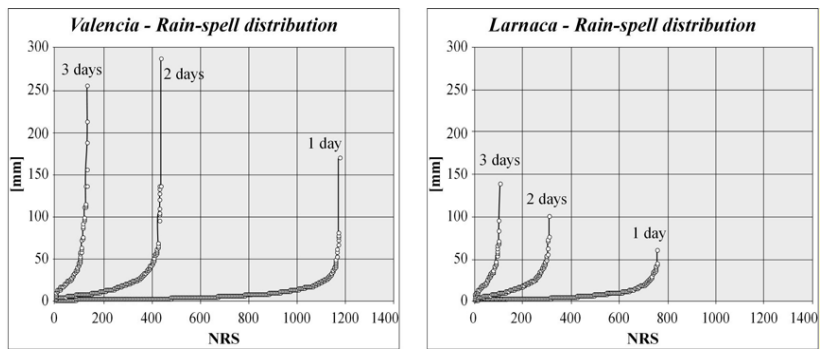

Fig. 9. The distribution of all rain-spells of $\mathrm{RSD}=1,2,3$ days.
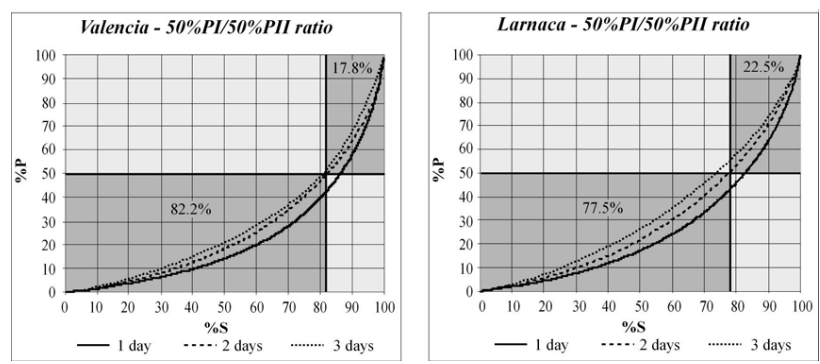

Fig. 10. Precipitation $\%$ \& rain-spells $\%$ relationship for $\mathrm{RSD}=1,2$, 3 days.

the definition of the Mediterranean climate is more suited to Larnaca than to Valencia (Fig. 11). Extreme values are evident also when the DSD is analyzed. The longest dry-spell recorded in Valencia during the analysis period, consisted of 119 days, from 21 June until 17 October 1978. This dryspell is 24 times longer than the median DSD, during the same period, which is only 5 days. In Larnaca, the longest dry period consisted of 211 days, from 31 March until the 27 October 1978. This dry-spell is 6.2 times longer than the median DSD, during the same period, which is 34 days. This ratio emphasizes again the greater uncertainty in Valencia as compared with Larnaca.

These above-mentioned parameters demonstrate that the two so-called Mediterranean stations, Valencia and Larnaca, have a different rainfall regime, although they are both classified under the same climatic definition. This is partially due to the fact that Valencia is located in an area within the Mediterranean basin with autumnal rainfall maximum, whereas in Larnaca rainfall maximum is usually during winter.

\section{Conclusions}

The parameters that compose the Most Expected Rainfall Regime, are a useful tool to understand the different rainfall regimes in a region. The classic definition of a Mediterranean climate limits the ability to track minor changes in the rainfall regime, while the details that these parameters present, show a large diversity. According to the MERR, the two Mediter-
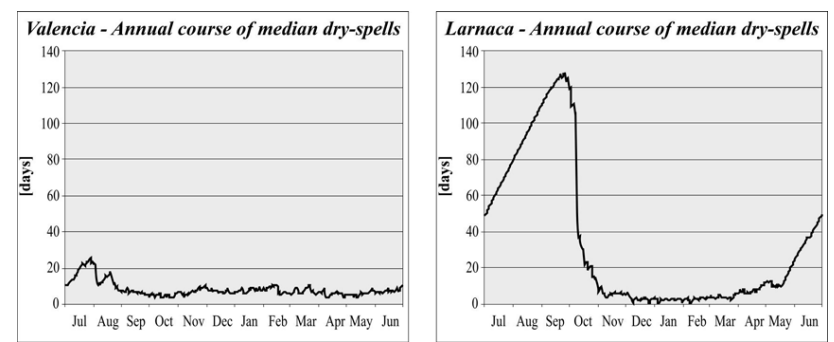

Fig. 11. Annual course of median dry-spells.

Table 1. 50\%PI, 50\% PII and their ratio for rain-spells of two days.

\begin{tabular}{lccc}
\hline & $50 \% \mathrm{PI}$ & $50 \% \mathrm{PII}$ & $50 \% \mathrm{PI} / 50 \% \mathrm{PII}$ \\
\hline Valencia & 82.2 & 17.8 & $\mathbf{4 . 6}$ \\
Larnaca & 77.5 & 22.5 & $\mathbf{3 . 4}$ \\
\hline
\end{tabular}

Table 2. AMED ratio for RSD of 1, 2, and 3 days.

\begin{tabular}{lccc}
\hline & RSD 1 DAY & RSD 2 DAYS & RSD 3 DAYS \\
\hline Valencia & $1.8 \%$ & $10.7 \%$ & $43.4 \%$ \\
Larnaca & $0.2 \%$ & $8.2 \%$ & $23.5 \%$ \\
\hline
\end{tabular}

ranean climate stations show different distributions in some of the parameters.

In Valencia, the rainfall regime has an uncertain character. The maximum TOTAL is 7 times higher than the minimum TOTAL. The longest RSL is 3.7 times the shortest rainy season and very inconsistent in its temporal evolution. The distribution of the rain-spells is very skewed, the precipitation of RSD of two days, for example, varies between $2.4 \mathrm{~mm}$ and $285.3 \mathrm{~mm}$. The ratio, between the rain-spells' precipitation and their occurrences, is high. Finally, the longest DSD is 24 times longer than the median one.

In Larnaca, the rainfall regime is less extreme, as compared with Valencia. The maximum TOTAL is 4.5 times higher than the minimum TOTAL. The longest RSL is 2.3 times the shortest rainy season and it is more consistent in its temporal evolution. The distribution of the rain-spells is more symmetrical, the rainfall of RSD of two days, for example, varies between $2.5 \mathrm{~mm}$ and $100 \mathrm{~mm}$. The $50 \% \mathrm{PI} / 50 \% \mathrm{PII}$ ratio of two days is not very high. The longest DSD is only 6.2 times longer than the median one.

The rainfall uncertainty is a combination of the deviations of all the parameters composing the MERR during the rainy period. In Valencia conditions are more variable and therefore the uncertainty is higher than in Larnaca. This larger variability in Valencia can be only partially attributed to the fact that the analysis period in that station is longer (66 yrs) 
as compared with Larnaca (52 yrs). Furthermore, as the median RSL in Larnaca is much shorter than in Valencia, 130 days as compared with 221 days respectively, the possibility for larger variations is smaller in Larnaca.

Even though Larnaca and Valencia are both on the Mediterranean coast, yet they differ in their climate. While Larnaca demonstrates a long, typical summer dry period, mainly to the southern and eastern Mediterranean, this cannot be said about Valencia. The present results enable to characterize both regimes in details, which will permit further studies to evaluate to what extent each year differs from the MERR.

Acknowledgements. The authors wish to thank N. Yoselevich for her excellent help with preparing the figures.

Edited by: P. Alpert, H. Saaroni, and E. Heifetz

Reviewed by: two anonymous referees

\section{References}

Alpert, P., Ben-Gai, T., Baharad, A., Benjamini, Y., Yekutieli, D., Colacino, M., Diodato, L., Ramis, C., Homar, V., Romero, R., Michaelides, S., and Manes, A.: The paradoxical increase of Mediterranean extreme daily rainfall in spite of decrease in total values, Geophys. Res. Lett., 29, 1-31, 2002.

Anagnostopoulou, C., Maheras, P., Karacostas, T., and Vafiadis, M.: Spatial and temporal analysis of dry spells in Greece, Theor. Appl. Climatol., 74, 77-91, 2003.

Aviad, Y., Kutiel, H., and Lavee, H.: Analysis of beginning, end, and length of the rainy season along a Mediterranean- Arid climate transect for geomorphic purposes, J. Arid Environ., 59, 189-204, 2004.

Ceballos, A., Martínez-Fernández, J., and Luengo-Ugidos, M.Á.: Analysis of rainfall trends and dry periods on a pluviometric gradient representative of Mediterranean climate in the Duero basin, Spain, J. Arid Environ., 58, 215-233, 2004.

Douguédroit, A.: The variations of dry spells in Marseilles from 1865 to 1984, J. Climatol., 7, 541-551, 1987.

Esteban-Parra, M. J., Rodrigo, F. S., and Castro-Diez, Y.: Spatial and temporal of precipitation in Spain for the period 1880-1992, Int. J. Climatol., 18, 1557-1574, 1998.
Gonzalez-Hidalgo, J. C., De-Luis, M., Raventós, J., and Sánchez, J. R.: Spatial distribution of seasonal rainfall trends in a Western Mediterranean area, Int. J. Climatol., 21, 843-860, 2001.

Houssos, E. E. Bartzokas, A.: Extreme precipitation events in NW Greece, Adv. Geosci., 7, 91-96, 2006, http://www.adv-geosci.net/7/91/2006/.

Kutiel, H.: The multimodality of the rainfall course in Israel, as reflected by the distribution of dry spells, Archive for Meteorology, Geophysics, and Bioclimatology, 36, 15-27, 1985.

Maheras, P. and Anagnostopoulou, C.: Circulation types and their influence on the inter annual variability and precipitation changes in Greece, in: Mediterranean Climate, edited by: Bolle, J. H., Springer, Germany, 215-239, 2003.

Martin-Vide, J. and Gomez, L.: Regionalization of peninsular Spain based on the length of dry spells, J. Climatol., 19, 537-555, 1999.

Norrant, C. and Douguédoit, A.: Monthly and daily precipitation trends in the Mediterranean (1950-2000), Theor. Appl. Climatol., 83, 89-106, 2005.

Palutikof, J. P. and Wigley, T. M. L.: Developing climate change scenarios for the Mediterranean region, in: Climatic Change and the Mediterranean, edited by: Jeftic, L., Keèkeš, S., and Pernetta, J. C., Edward Arnold, London, 27-54, 1992.

Paz, S. and Kutiel, H.: Rainfall Regime Uncertainty (RRU) in an Eastern Mediterranean region a methodological approach, Israel J. Earth Sci., 52, 47-63 2003.

Reiser, H. and Kutiel, H.: Rainfall uncertainty in the Mediterranean: Definition of the rainy season - a methodological approach, Theor. Appl. Climatol., doi:10.1007/s00704-007-0343z, 2007.

Tomozeiu, R., Lazzeri, M., and Cacciamani, C.: Precipitation fluctuations during the winter season from 1960 to 1995 over EmiliaRomagana, Italy, Theor. Appl. Climatol., 72, 221-229, 2002.

Türkeş, M.: Spatial and temporal analysis of rainfall variations in Turkey, Int. J. Climatol., 16, 1057-1076, 1996.

Steinberger, E. H. and Gazit-Yaari, N.: Recent changes in the spatial distribution of annual precipitation in Israel, J. Climate, 9, 33283336, 1996.

Wigley, T. M. L.: Future climate of the Mediterranean basin with particular emphasis on changes in precipitation, in: Climatic changes and the Mediterranean, edited by: Jefitic, L., Milliman, J. D., and Sestini, G., London, Edward Arnol, 15-42, 1992. 